\title{
Artículos
}

\section{¿Es el crecimiento la locomotora de nuestra economía?}

\author{
Francisco Javier Ibisate
}

\section{Resumen}

Para la teoría de la globalización, el crecimiento constituye el principal parámetro de la salud económica, pero éste, por sí solo, no conforma la locomotora de la economía. Durante 20 años se han enfrentado, al menos, seis enfermedades económicas inmanentes al crecimiento, es decir, fenómenos mundiales que son consecuencias de pasados comportamientos globales. Entre ellos, el crecimiento frenado con alza de precios (estanflación); el deterioro ecológico; la exclusión del trabajo (crecimiento con desempleo); la desigualdad dentro del crecimiento mundial; la falta de integración de todos los sectores productivos, y la inversión especulativa por la privatización de servicios públicos y en el mercado del capital financiero. Por tanto, es prioritario que quienes integran la demanda y la oferta deficientes, elaboren propuestas económicas que enfaticen medidas concretas con miras hacia la integración sectorial.

Luego de varias décadas de énfasis en el crecimiento, tanto en las economías de mercado como en los modelos de planificación central o simplemente indicativa, así como en las teorías de la dependencia, ahora son muchos los autores que recomiendan hacer un alto en el camino y una reformulación del contenido, del modo y de la dirección del crecimiento económico. Esta reflexión es más necesaria porque la teoría de la globalización -y nuestros informes oficiales- hace del crecimiento el parámetro prioritario de la salud económica. La reflexión es necesaria porque nos 
hallamos en un difícil dilema: al mismo tiempo que sentimos la necesidad del crecimiento tomamos conciencia de que éste, por sí sólo, no es la locomotora de la economía porque encuentra límites infranqueables y genera diversos efectos negativos. La misma historia nos obliga a hacer un alto y una reformulación de nuestra teoría del crecimiento.

El presente artículo no es un discurso sobre las teorías del crecimiento, propias de un curso de desarrollo económico. Se trata de una lectura histórica de las tres últimas décadas, a nivel mundial y nacional, desde un enfoque de autocrítica de nuestro crecimiento: sus límites o fronteras, sus dificultades e incluso sus efectos adversos. Desde 1993, y más recientemente 1996-1997, diversas propuestas económicas muestran una inconformidad con el rumbo actual y presentan nuevas sendas para el desarrollo. Con la desintegración política y económica de los llamados socialismosreales, parecería que sólo resta un determinado modelo de producción y crecimiento. Pero también a este modelo hay que confrontarlo con su historia: sus ideales, principios y objetivos con la realidad y consecuencias históricas. Asimismo nos ha podido suceder que, sin modelo alguno, nos dejamos arrastrar por la corriente mundial sin dirección y rumbo alguno. Bajo esta hipótesis no seríamos dueños de nuestro destino, sino que estaríamos a merced de un desarrollo por dependencia. Una autocrítica de nuestro crecimiento, dentro de la gran corriente mundial, es una forma de conocer de dónde venimos y hacia dónde vamos.

En el término de veinte años hemos generado y enfrentado al menos seis enfermedades económicas inmanentes al crecimiento y que hacen más difícil formular programas y políticas nacionales; estas propuestas tropiezan rápidamente con cuellos de botella. Llamo enfermedades a estos fenómenos mundiales porque no deben su existencia a una causa exógena (la corriente del Niño), sino que son consecuencias de pasados comportamientos globales. Sería más apropiado hablar de coyunturas, en el sentido etimológico de esta palabra. Coyuntura es un concepto latino que no indica una situación presente, sino un resultado futuro: cumiunctura literalmente enuncia o anticipa una situación futura, resultado de la conjunción de varias acciones pasadas. Es lo mismo que decir que el futuro lo estamos construyendo desde el presente y que en el presente bebemos el agua que viene de río-arriba. Aunque la economía es una ciencia so- cial, los actos humanos no son siempre racionales ni razonados y derivan en resultados contradictorios. Puesta esta aclaración, el autor enuncia esas seis coyunturas entrelazadas e interdependientes de la reciente historia.

\section{Las coyunturas del crecimiento económico}

Se hace una breve referencia a los hechos más conocidos, alargando el comentario en aquellos que parecen presentar alguna novedad o, por lo menos, una lectura novedosa.

\section{A. La estanflación}

En 1970, luego de veinte años de tasas elevadas de crecimiento ("milagros económicos") y desgastante carrera armamentística, aparece el fenómeno de la estanflación, crecimiento frenado con alza de precios. El fenómeno es novedoso porque en las décadas anteriores o los ciclos económicos, las alzas aparecían después de algunos años de recuperación y prosperidad que terminaba en tensión económica. La recesión subsiguiente integraba un crecimiento frenado o declinante junto con la caída de los precios. Los nuevos ciclos económicos presentan, a nivel mundial, los síntomas de la estanflación. Las tasas de crecimiento del Producto Interno Bruto (PIB) en los países industrializados de la Organización de Cooperación para el Desarrollo Económico (OCDE) son los siguientes: 1960-1968, 5.1 por ciento; 1968-1973, 4.7 por ciento; 1973-1979, 2.6 por ciento; 1979-1988, 2.2 por ciento. Para 1992, el Fondo Monetario Internacional reporta un crecimiento del 1.5 por ciento para la economía mundial, al mismo tiempo que se agudizan los problemas de inflación, desempleo y déficit fiscal.

Por razones normales y anormales, nuestra economía sigue un rumbo semejante: la década de los setenta mantuvo tasas promedio anuales del 5 por ciento; el conflicto bélico conjugó la declinación del crecimiento con elevadas alzas de precios, y luego del auge ficticio 1992-1995 nos hallamos en una fase de estanflación. Nuestro proceso inflacionario ha cumplido veinticinco años y su efecto ha sido destructivo expresado en salarios reales. Si la inflación afecta a los salarios reales, su caída genera más recesión.

\section{B. El deterioro ecológico}

Un segundo fenómeno o enfermedad mundial se anuncia, a modo de seria advertencia, en el in- 
forme del Club de Roma, 1972, y señala los límites del crecimiento derivados del agotamiento del "tesoro inagotable de la naturaleza". Es claro que este deterioro de los recursos naturales explica, en gran parte, la onda declinante del Kondratief de 1970 a nuestros días. El choque petrolero,1973..., es sólo un botón de muestra. La cumbre de Río de Janiero y el estudio de Al Gore, "La tierra en jue-" go", destacan este límite mundial del crecimiento económico. El agotamiento del medio ambiente es un "sida" económico, y los ecologistas nos advierten que la naturaleza herida nos devuelve el boomerang del cáncer.

El nuevo sistema de contabilidad nacional suprimió, desde 1995, la deducción de la "depreciación del capital" en los cálculos del Producto Nacional Neto, lo que el país puede producir sin empobrecerse. Debido a dificultades de estimación estadística se deja en la cámara oscura uno de los límites mayores de nuestro crecimiento; nuestros Productos Internos Brutos y Renta siguen siendo "Brutos". Luego de cálculos que hicieron algunas instituciones nacionales, en reciente publicación sobre el desarrollo sostenible, FUSADES nos informa y muestra que nuestro crecimiento real ha sido "cero"; el total de pérdidas estimadas por la degradación ambiental ronda los 500 millones de dólares anuales, una suma equivalente al 5 por ciento del Producto Interno Bruto' . Esto significa que ya comenzamos a decrecer desde 1996; pero, sobre todo, nos enfrenta a la difícil frontera de nuestro crecimiento. Por supuesto que este serio estudio no se queda en marcar los límites sino en dar pautas y soluciones, que merecen lectura y seria reflexión. Las autoridades gubernamentales asistieron a la exposición y, sin embargo, afirman que seguimos creciendo.

\section{Crecimiento con desempleo}

Desde finales de la década de los sesenta y más aún en la presente década, Cumbre de Copenhague, en 1995, aparece la contrariedad del crecimiento con desempleo (jobless-growth) en los cuatro mundos de la misma globalización; su causa, ¿está en la febril revolución tecnológica? Al igual que en la década de 1930, un fantasma recorre el mundo: el desempleo, y su acólitó, la pobreza generalizada. En los documentos de antecedentes de Copenhague, Boutros Ghali hablaba de una crisis de trabajo en un entorno de crisis económica, crisis social, crisis moral, crisis de incertidumbre o colapso mundial, que reproduce un darwinismo-social de ricos y pobres, todo lo cual deriva en el incremento de delitos internos y externos al núcleo familiar. Este doliente fenómeno es fácil de sentir y observar a nivel nacional, donde el crecimiento encuentra los límites de la inflación, del agotamiento ecológico, del desempleo y de la inseguridad social. Por lo menos deberíamos ser más honestos al dar las estadísticas de estas realidades. Este estilo de crecimiento guarda estrecha relación con las tres coyunturas siguientes.

\section{Crecimiento con equidad}

Sin seguir un orden cronológico, porque la historia es una coyuntura de varias coyunturas, desde las teorías de la dependencia hasta la CEPAL ("Equidad y transformación productiva: un enfoque integrado") ${ }^{2}$, se prolonga el debate sobre crecimiento y equidad. La tesis liberal y sus locutores nacionales presentan un proceso en dos fases secuenciales: primero, el crecimiento global y, luego, en un tiempo indefinido o escatológico, llegaría el "derrame" social. Esta postura aparecía en

1. FUSADES. "El desafío salvadoreño: de la paz al desarrollo sostenible", mayo, 1997; PRISMA. "El Salvador: dinámica de la degradación ambiental", julio, 1996; Rubio R., Germain A. y Góchez R. "La situación ecológica de El Salvador", UCA-Editores, 1996.

2. CEPAL. "Equidad y transformación productiva: un enfoque integrado", Santiago de Chile, 1992; "Imágenes sociales de la modernización y la transformación tecnológica", Santiago de Chile, 1995. 
el plan de desarrollo 1989-1994 y todavía es la postura del actual gobierno, asimismo se sostiene entre líneas y fuera de líneas en el Manifiesto Salvadoreño de la Asociación Nacional de la Empresa Privada (ANEP).

Las teorías sociales, desde los Estados de bienestar (libertad, igualdad y fraternidad) enfatizan en el enfoque integrador del crecimiento con equidad; si la oferta puede crear la demanda, más cierto es que la demanda crea la ofertá cuando se trata de la demanda laboral. En 1993, año preelectoral, varios institutos nacionales (CENITEC, IIES-UCA, FUNDE, FUSADES, etc.) debatían sobre la necesidad y posibilidad de integrar ambos objetivos, apoyados en las investigaciones de la CEPAL. No todas las instituciones mantenían la misma posición y dejamos un esbozo del debate en nuestra revista Realidad Económica y Social?. Como el debate era continental e intercontinental, hicimos referencias a dos importantes seminarios: "El neoliberalismo en cuestión", Barcelona, 1993, y "Etica, economía, política y pobreza", Bogotá, 1995. Entre las múltiples referencias sobre este debate, merece citarse el artículo de Frank Hinkelammert: "El huracán de la globalización" que utilizaré en el presente comentario. Las citas obedecen al hecho de que hoy todos estamos de acuerdo en que la teoría del derrame no ha funcionado ni a nivel nacional, ni a nivel mundial, incluidos los países desarrollados donde también los ricos se hacen más ricos y los pobres más pobres. La desigualdad es otra compañera de vida del crecimiento mundial.

\section{E. El crecimiento armónico}

Con el advenimiento del neoliberalismo de mercado y su rechazo a cualquier planificación que no sea la del mercado, se ha relegado la preocupación por el crecimiento armónico o integración de todos los sectores productivos. El crecimiento armónico ha sido parte sustancial de la contabilidad nacional y de la macroeconomía nacida luego de la segunda guerra mundial. El economista, de origen ruso, W. Leontief, se ganó el pre- mio Nobel por descubrir y describir las sendas del desarrollo, el crecimiento armómico, con el radar de las matrices intersectoriales. Aunque los fisiócratas, con su Cuadro Ecónomico, echaron la semilla, ha sido un aporte del presente siglo el cuantificar y detallar la interdependencia e interrrelación de todas las ramas económicas. Con el advenimiento de la economía de mercado y del reducionismo al simple crecimiento global se echa un velo tupido sobre el crecimiento deforme de nuestra terciarización económica.

Como lo habían advertido hace años CENITEC, IIES-UCA, FUNDE y los escritos de ANEP y FUSADES, el olvido del crecimiento armónico hace prácticamente imposible el crecimiento sostenido que, sumado al agotamiento ecológico, dificulta seriamente el crecimiento sostenible y el crecimiento con equidad. Sobre este aspecto volveremos con más detalle posteriormente. Esta es la coyuntura que hemos ido gestando entre todos, y nuestros gobiernos tienen su dosis de culpabilidad por acción u omisión de sus políticas económicas. Tristemente, cada coyuntura arrastra hacia coyunturas más conflictivas.

\section{F. Los crecimientos especulativos}

Con el huracán de la nueva globalización, porque globalización siempre ha habido, se ha gestado un doble obstáculo al crecimiento real o, si se quiere, una doble alternativa a la inversión productiva: se trata, en primer lugar, de la inversión especulativa por la privatización de servicios públicos, normalmente en compañía de la inversión extranjera y, en segundo lugar, de la inversión especulativa en el poderoso mercado del capital financiero. Esta parte requiere recordar algunos antecedentes nacionales y una presentación del escenario mundial.

El sector productivo salvadoreño, público y privado, del cual somos parte, resiente un serio rezago tecnológico debido no sólo al prolongado conflicto bélico, sino también a la aversión del mismo riesgo tecnológico; ésta es una característica que viene de pasadas décadas (ECA, 1997, pp.

3. Ibisate, F. J. "Piezas para un modelo económico", Realidad Económica Social, No 35, 1993; "Propuestas de bienestar ¿con Estado de bienestar? ECA, No 576, 1996.

4. Varii. "El neoliberalismo en cuestión", Sal Terrae, 1993; Varii. "Etica, economía, política y pobreza: el desafío crucia para Latinoamérica", Santa Fé de Bogotá, 1995; Hinkelammert F. "El huracán de la globalización", Economía informa, UNAM, México, 1997. 


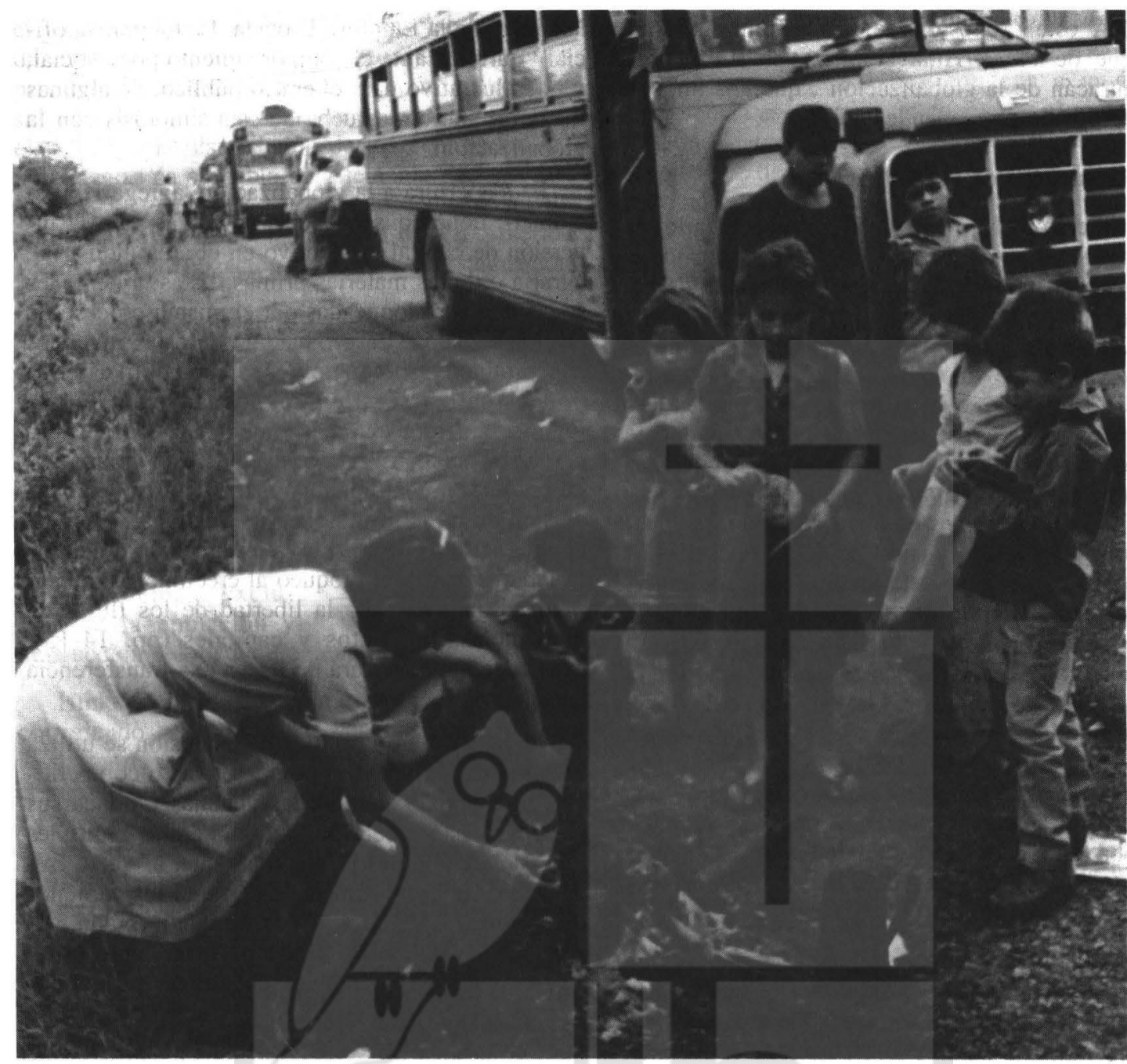

374 y 546). Adicionalmente, la grave terciarización económica, en parte retroalimentada por el sesgo del crédito bancario, va reduciendo el espacio u oportunidades de "nichos" atractivos en los sectores manufacturero y agropecuario. El sector y el capital privados al argumentar la ineficiencia del sector público y silenciar su escasa capacidad competitiva, reclaman la cohabitación con la inversión extranjera en los servicios públicos más rentables, que engrosan la lista de la privatización. Esta invasión o cacería forma parte de la corriente mundial y los gobiernos prestan su mayor apoyo. Los gobiernos sirven a la globalización que abate las fronteras.
Salvador O. Brand afirma que:"en El Salvador no estamos bien informados sobre la amarga realidad de la globalización económica y se divulga como si éste fuera un fenómeno novedoso, surgido en los años noventa... En cuanto a la globalización, tanto el sector público como el privado deben ser más conscientes al vender a los empresarios un panorama idealizado de las oportunidades que ofrece la globalización, pues a la par deben divulgarse los requisitos y los riesgos por enfrentar". ( $E C A, 1997$, pp. 545- 548.) El debate no es si entramos o no entramos en la globalización, sino analizar cómo la amarga realidad de la globalización está ya afectando nuestras econo- 
mías. A este propósito me parece iluminador el enfoque de Frank Hinkelammert, en su artículo "El huracán de la globalización", que nos impone un "desarrollo por dependencia".

\subsection{El huracán de la globalización}

Hinkelammert presenta al primer mundo de hoy como un archipiélago que aparece en todos lados, en el interior de un mar circundante de espacios que ya no pueden integrarse ni económica ni socialmente. Incluso, los países del primer mundo dependen de un crecimiento intensivo, altamente tecnificado, que ha logrado los límites tecnológicos posibles y que puede seguir solamente al paso del surgimiento de nuevas posibilidades tecnológicas y de su aprovechamiento. A excepción de las inversiones en infraestructura, las nuevas inversiones son función de nuevos desarrollos tecnológicos. Aunque este archipiélago de inversiones intensivas en alta tecnología está ubicado sobre todo en el norte, esta relación no puede entenderse como una relación norte-sur, sino como una relación de exclusión;" hoy día se habla de un tercer mundo al interior del primer mundo y de un primer mundo en el tercero". Lo que tenemos son centros o enclaves en forma de archipiélago y una periferia circundante, donde el mercado mundial engloba todo, dada la libertad de los flujos de mercancías y capitales y la ausencia de intervenciones estatales a estos flujos.

Hinkelammert agrega una acotación bastante iluminadora: ausencia de intervenciones estatales no significa ausencia del Estado."La globalización no es posible sin una acción constante y decidida de los Estados. Ahora, los Estados funcionan, sobre todo, como instancias de la globalización, que debe facilitar los flujos de mercancías y capitales $y$ fomentarlos con subvenciones inmensas y que en tamaño superan la cantidad de subvenciones que el Estado social jamás haya efectuado. Solamente en esa forma se considera la competencia como el verdadero motor de la globalización y la victoria de la competencia como eficiencia" (p.14). Somos testigos de los constantes reclamos y la costosa publicidad con que el gobierno trata de diseñar una imagen atractiva para la inversión extranjera, que se muestra bastante recelosa de posarse en algunos nidos dada la permanente ola de violencia-inseguridad. Estos reclamos aparecen en el reciente discurso del primero de junio y también en el Manifiesto Salvadoreño de la Asociación
Nacional de la Empresa Privada. La tolerancia oficial y jurídica ante el comportamiento poco social, y poco lucrativo para el erario público, de algunas maquilas son otra prueba de esta simbiosis con la globalización.

Esta apertura a la globalización, agrega Hinkeammert, tiene consecuencias negativas para la inversión de capital productivo en el área industrial, agraria o de las materias primas. Estas inversiones se pueden ver bloqueadas por el mismo proceso de la globalización. La producción de estas inversiones productivas requieren ser competitivas para poder realizarse, lo que pocas veces puede lograrse sin protección y fomento; en consecuencia, no se inician. Los enclaves de este archipiélago conservan una dinámica hacia dentro y una exclusión de otras inversiones productivas. " Así, se explica la tendencia hacia la estagnación dinámica (jobless-growth), el bloqueo al crecimiento del capital productivo, ante la libertad de los flujos de mercancías, productos y capitales"(pp. 14-15). Más adelante se tratará de hacer una transferencia de estas tesis a nuestra realidad.

En apoyo a esta política de exclusión se utiliza la teoría de las ventajas comparativas o competitivas, ponderando siempre las ventajas y nunca sus pérdidas. Esto afecta de manera seria a múltiples inversiones internas productivas que, al verse frenadas por la competencia, hacen que los capitales disponibles sean invertidos especulativamente. Aparece, entonces, la cacería de inversiones especulativas de mayor rentabilidad. Estas posibilidades de inversiones especulativas se hallan, sobre todo, en aquellos sectores situados hasta ahora fuera del ámbito de la rentabilidad, es decir, en servicios públicos y sociales del Estado. El capital especulativo no encontraría ubicación rentable sin invadir estas actividades. "Esto explica la presión mundial hacia la privatización de todas las funciones del Estado para encontrar esferas de inversión no productivas... Cualquier actividad humana tiene que ser transformada en esfera de inversión de capital para que pueda vivir el capital especulativo: escuelas, jardines infantiles, universidades, sistemas de salud, carreteras, la infraestructura energética, los ferroccarriles, el correo, las telecomunicaciones, los otros medios de comunicación"...(p.15).

Este proceso de globalización-privatización, al generar una nivelación de salarios a la baja y una concentración mayor de los ingresos, incrementa 
el volumen de capitales disponibles y necesitados de nuevas inversiones especulativas. "Las privatizaciones, que se buscaban como solución y salida, llevan a la agudización del problema y con el tiempo a la disminución de los centros del archipiélago. Ya se habla en Alemania de la sociedad de la tercera parte hacia la sociedad de la quinta parte de la población" (p.16). En América Latina, la globalización acentúa esta estagnación dinámica, donde el desarrollo se hace con menos fuerza de trabajo. Esta fuerza de trabajo "liberada" tiende a refugiarse en el sector informal en situación de precaria subsistencia. Por tanto, se discuten soluciones posibles a partir de estos dos problemas: exclusión de la población y destrucción del medio ambiente.

Hinkelammert llega a la siguiente conclusión, corrigiendo la teoría de las ventajas competitivas. "Esta teoría sostiene que cualquier forma de libre comercio internacional necesariamente se aplica en ventaja de todos los países que entran en este comercio. El peor de los casos concebidos es el caso en el que un país no obtenga ventajas, pero la teoría excluye la posibilidad de que un país pierda por aceptar el libre comercio. Según esta teoría, no es posible que comprar barato sea la manera más cara de comprar. Sin embargo, la transición al estancamiento y después a la contracción dinámica son completamente diferentes. En esta situación, el libre comercio destruye mayores ingresos de los que se generan derivados de la compra más barata. Efectivamente, se compra más barato, pero esta compra lleva a la destrucción de producción que había permitido determinados ingresos. Al destruir esta producción, sin sustituirla por nueva y más eficiente, se pierde este ingreso sin ninguna contrapartida igual o mayor"... (p.15).

Más adelante, se vuelve a similar reflexión desde los efectos de la exlusión de la población. "Si la exlusión de la población resulta inevitable dentro de cualquier política de crecimiento, hace falta enfrentar la misma economía de crecimiento si se quiere una solución a este problema. Dado el estancamiento dinámico no se puede tener la competitividad como criterio central del desarrollo económico. La competitividad resulta en que siempre hay quien gana y quien pierde. Para quien pierde esto equivale a una condena a muerte. Competencia es una especie de guerra; el mercado no es un juego. Es una guerra con todas las consecuencias que tiene la guerra. Un desarrollo generalizado no es posible más que al intervenir los mercados de una manera tal que aquel que pierda en la competencia no sea condenado a la muerte. Por esta razón, el perdedor de la competencia tiene el derecho de protegerse $y$ es bien racional el que lo haga. Al ser eliminado de la competencia pierde mucho más de lo que podría ganar con los efectos positivos de la competencia. Por tanto, no debe aceptar el juicio del mercado. Producciones no competitivas son económicamente racionales siempre y cuando las ventajas de la competencia -es decir, al acceso a bienes más baratos-sean superadas por las pérdidas de ingresos por medio de la eliminación de las producciones no competitivas" (p. 18).

Esta situación del océano que circunda al archipiélago, dinámico hacia dentro y exluyente hacia fuera, lleva a F. Hinkelammert a proponer una política de protección de ciertas producciones no competitivas, en razón del amplio estancamiento dinámico o crecimiento con desempleo.

A modo de ejemplo se expone el desarrollo de los "tigres asiáticos", que no surgen por un sometimiento al proceso de globalización, sino más bien aprovechando la oportunidad que ella ofrecía: un entrelazamiento del Estado y de la estructura empresarial que fomenta y protege las empresas nacionales para que puedan introducirse en el mercado internacional. Esta planificación económica utilizó los medios tradicionales para defenderse de la competencia externa y fortalecer sus ventajas competitivas. No ha sido ésta la política aplicada a nivel del continente latinoamericano. Ander Gunder Frank dice que "América Latina es el continente de la lumpenburgesía", que sigue exportando mayoritariamente productos agrícolas y minería, sin mayor exportación industrial.

Aunque en la segunda parte del presente artí- 
culo se desea hacer un aterrizaje en el campo nacional, la exposición de Frank Hinkelammert ayuda a entender por qué, al reducirse los nichos productivos de los sectores agrario y manufacturero y al encontrar los límites del agotamiento ecológico, el sector privado pretende invadir servicios públicos relativamente más rentables, cuando ha demostrado escasa eficiencia

$y$ competitividad en sus propios feudos. Queda por buscar una explicación a la otra alternativa que desvía crecientes montos de ahorro-capital hacia la especulación en el poderoso mercado financiero. Con-
La especulación financiera genera una inestabilidad monetaria e imprime lentitud al crecimiento económico. por ciento a un 2.5 por ciento anual)... Esta inestabilidad favorece al capital especulativo, de tal manera que hoy las tasas de beneficio de las instituciones bancarias (resultado del comercio de divisas) son las tasas de beneficio más altas de todas las actividades empresariales del mundo. (El premio Nobel James Tobin proponía imponer cargas fiscales (tax-Tobin) a estos flujos, y dedicarlas a un fondo para el desarrollo (PNUD), superando esta irracionalidad económica). Esta globalización financiera $\multimap$ sociedad internacional de "casino"- es la viene reflexionar sobre los sonoros fraudes financieros y el espíritu de especulación que deslumbró a los propios ahorrantes. ¿Son comportamientos individuales o es reflejo de una ética del mercado?

\subsection{La inversión especulativa en el mercado fi- nanciero}

Hasta hace pocos años, lo normal era decir que los ingresos de la población, en sentido amplio, se canalizaban en parte al consumo y el resto al ahorro que se destinaba hacia la inversión. Un nuevo límite que hoy encuentra el crecimiento real es que un porcentaje elevado de ese ahorro-capital se desvía a la inversión especulativa a través del atractivo mercado financiero. La rentabilidad inmediata prevalece sobre la producción a mediano plazo y la especulación sobre la creatividad tecnológica. A partir de datos estadísticos, el mercado de capitales financiero moviliza diariamente 1.2 trillones de dólares. "En cuatro días de transferencias bancarias internacionales, resultado de las transacciones de divisas, se manipula más dinero que toda la producción creada por la economía de Estados Unidos en un año, o por la economía mundial en un mes"'.

La especulación financiera genera una inestabilidad monetaria e imprime lentitud al crecimiento económico. Así se expresaba el anterior gobernador del Banco de la Reserva Federal de Estados Unidos, Volcker: "Desde principios de los años setenta el crecimiento económico de los países más desarrollados se ha reducido a la mitad (del 5 que se conoce en lenguaje popular como mercado financiero, a los que se asume dictan las políticas económicas y sociales de los gobiernos".

Estas citas y referencias estadísticas nos recuerdan que la globalización integra, al menos, tres grandes y libres mercados: el mercado de la producción de bienes y servicios de alta tecnología, controlado por el archipiélago de las multinacionales; el mercado mayor en volumen y poder del capital financiero, que impone las políticas a los gobiernos nacionales y que ha generado, de 1987 a 1994, la aparición de 358 bimillonarios, cuyos ingresos (762,000 millones de dólares) igualan las rentas de unos 2,300 millones de personas más pobres. Y el mercado de la información y medios de comunicación social, que técnica y descaradamente nos impregna del espíritu financista e insolidario de la neo-globalización. El ha dicho que: "La bolsa de valores funciona mejor que las Naciones Unidas. Los financieros anticipan la evolución de la humanidad. Pero, ¿es a ellos a quienes corresponde conducirla? y $¿ \mathbf{a}$ benefício de quién?

Estos tres mercados se unen, entrelazan y defienden. Las multinacionales se autodefienden de la competencia y no tienen una nacionalidad específica, porque cada una retiene elevadas participaciones en las acciones de las otras megaempresas; puede ubicarse en el territorio nacional de la competencia aparente y moviliza en la bolsa de valores arzobispo de París, Monseñor Jean Marie Lustiger,

5. Navarto V. "En contra del determinismo económico”, El País, Madrid, julio, 1997; Gorostiaga X. “¿Qué educación?, ¿para qué desarrollo?", Seminario: Reforma y Ley de Educación, Managua, 1996. 
las más variadas divisas. Se redescubre el refrán: el mayor beneficio del oligopolio es la tranquilidad, las coaliciones o convenios $y$, en última instancia, las fusiones. Si la globalización asienta su fuerza y dominio en la propiedad del conocimiento tecnológico, también es cierto que genera un subproducto dañino, la práctica de la especulación financiera, que se alimenta y crea vaivenes en el sector real de la producción. Si hay expertos en inventar e innovar, también hay expertos en especular y beneficiarse del trabajo ajeno.

Por añadidura, proliferan otras perversas especulaciones. Si en décadas pasadas se dedicaron cantidades ingentes a la desgastante carrera armamentística, relegando con ello la producción de bienes civiles, terminada la guerra fría se suman los 700 billones de dólares anuales del "mercado del crimen" (narcotráfico, prostitución...), los 800 billones de dólares anuales del mercado "oficial" de armas y los 762 billones de dólares de los 358 bimillonarios, en buena parte derivados de la bolsa de valores. Aparte de que estos flujos trillonarios desvían ingentes capitales de la producción mundial civil, ponen de manificsto que el mercado globalizado está sometido a los imperativos de estas dañinas especulaciones. Suele citarse como ejemplo el mal ejemplo del gobierno conservador de Inglaterra. Al mismo tiempo que se aplicaban severas políticas de austeridad fiscal, reduciendo la inversión y seguridad social, el principal centro financiero, The City, manipulaba un flujo diario de 460 billones de dólares, sólo en el comercio de divisas, cuyos beneficios hubieran bastado para erradicar la pobreza del país. La especulación pasa de largo frente a la pobreza y el desempleo; éste es el mundo en que vivimos.

Detengámonos a pensar un momento en el impacto que ejercen sobre nosotros los medios de comunicación social, las puertas que nos abre el internet y los tiempos que dedican a la evolución de la bolsa mundial o mercado de dinero, y podremos entender que la especulación financiera impregna las conductas de los agentes bancarios, de los clientes de nuestras bolsas de valores y hasta de los defraudados depositantes de InseproFinsepro... La especulación financiera desvía grandes flujos de ahorro-capital de la inversión pro-

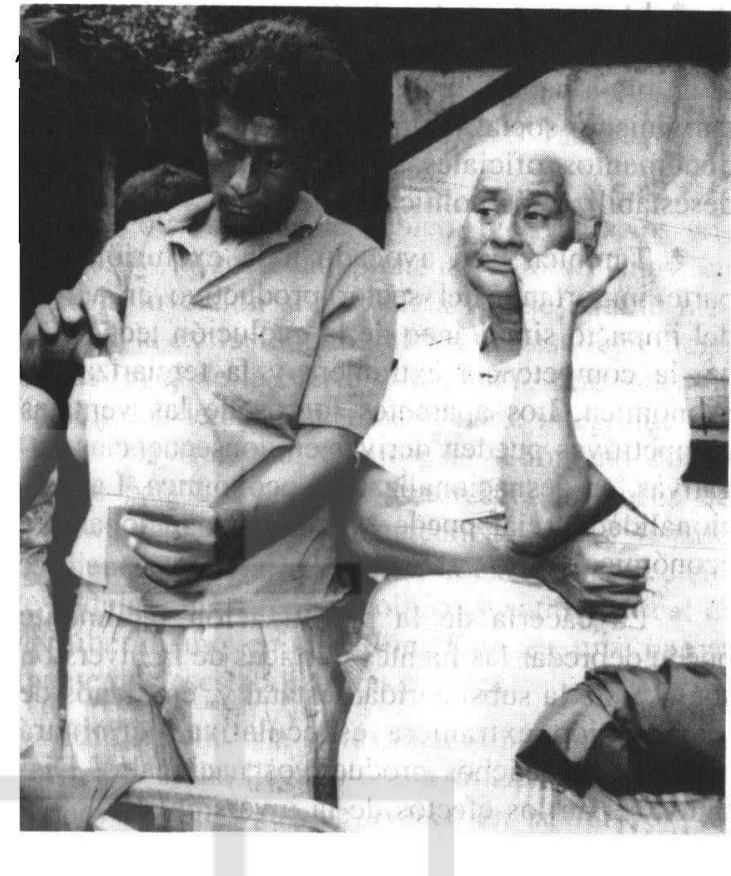

ductiva o crecimiento real, y a sus tiempos castiga a los mismos especuladores. El mercado de dinero también es una guerra donde alguien gana y muchos pierden. La especulación domina una parcela de nuestra coyuntura nacional. Por ello, sumando coyuntura a coyuntura, nos preguntamos si el crecimiento genera crecimiento y si él es la locomotora de la economía. Hay que rehacer la teoría del crecimiento.

\subsection{Reflexiones sobre nuestras coyunturas eco- nómicas}

Si este entrelazamiento de coyunturas responde a tendencias_históricas, estamos enfrentados a graves consecuencias antisociales y antieconómicas. Se subraya la expresión "tendencias históricas" para indicar la presencia de fuerzas o movimientos de fondo que arrastran al conjunto de economías, de acuerdo con cumbres mundiales (El Cairo, Río de Janeiro, Copenhague, Beijing...), informes continentales (Cartagena de Indias, Neoliberalismo en América Latina...) así como la diversidad de propuestas y programas nacionales de reformulación económica ${ }^{6}$. He aquí algunos signos externos.

6. Varii, S. J. "El neoliberalismo en América Latina", Editorial Opciones Gráficas, México, noviembre, 1996; Ibisate, F. J. "Pobreza, desempleo e integración social", Realidad, No 42, 1994. 
* El gran perdedor de la presente revolución histórica es el factor trabajo; su exclusión creciente da pie a hablar de una masiva proletarización y darwinismo social. Estas expresiones aparecen en documentos oficiales y presagian la inmanente desestabilización política.

* También está avocado a la exclusión una parte importante del sector productivo en virtud del impacto simultáneo de la evolución tecnológica, la competencia extranjera y la terciarización económica. Los aparentes logros de las ventajas competitivas pueden derivar en consecuencias negativas, en desnacionalización económica. La irracionalidad social puede surgir de la racionalidad económica.

* La cacería de la privatización fácilmente puede depredar las fuentes públicas de la inversión social y de la subsidiaridad estatal y, en manos de la inversión extranjera especulativa, terminará agotando los nichos productivos nacionales. Distintos serían los efectos de la inversión extranjera producliva, que se ubique como escuela de aprendizaje tecnológico y factor de integración económica sectorial.

* El agotamiento de nichos productivos, en el sector real privado y público, desvía elevados montos de ahorro-capital hacia la especulación del mercado financiero, cuya rentabilidad es aleatoria si el sector real se reduce y pierde competitividad.

* Este proceso de desnacionalización económica, sustentado en la rentabilidad a corto plazo, deriva a la economía informal de subsistencia, que hoy día se ha convertido en un punto de atención y preocupación por englobar la mitad de la mano económicamente activa y ser un creciente puntal del Producto Interno Bruto nacional. La economía informal sería la más nacional o popular, dado que se van cerrando otras vías de salida geográfica a la población, a menos que avancemos en una verdadera unión económica centroamericana.

Cinco hechos relevantes de nuestro pasado histórico pueden aportar una explicación aproximada de este proceso nacional:

* El rezago o, más bien, la reticencia a la innovación tecnológica que ha caracterizado al sector privado y también al sector público en las pasadas décadas.

* El irrespeto y agotamiento de los escasos recursos naturales y el uso antisocial de los bienes públicos. La guerra prolongada ha agregado su dosis de exterminio a estos dos primeros límites del crecimiento económico.

* Un derivado ha sido el deslizamiento hacia una deforme terciarización económica, con sus negativas consecuencias en la gestación de valor agregado, empleo e ingresos.

* El descuido real, por múltiples razones, de la inversión social o formación del capital humano, que obliga a dedicar hasta un 14 por ciento del Producto Interno Bruto en gastos directos e indirectos del control de la inseguridad nacional.

* Un crecimiento inadecuado e irresponsable de la población, que tiene sus raíces en la descomposición del núcleo familiar, la cultura machista y la dañina inculturación de los medios de comunicación social, que destruyen valores fundamentales. Las grandes víctimas son mujeres y niños.

* A este listado se podría agregar la corrupción, el tráfico de influencias y el ocultamiento de la verdad, que son normas de conducta en diversas esferas sociales y que desvirtúan los principios éticos básicos de la convivencia ciudadana.

Si estas afirmaciones tienen cierta dosis de verdad, tal como aparece en las encuestas de opinión pública y los programas económicos nacionales, merece la pena un momento de reflexión y de enmienda porque no puede ser éste el fin de la historia. Un problema por discutir es si las seis o más coyunturas antes mencionadas se relacionan cada una con la anterior (post hoc, ergo propter hoc), o más bien se entrelazan y retroalimentan. Este entrelazamiento dificulta presentar un orden prioritario de acción en ese mosaico de propuestas nacionales abiertas al diálogo.

\subsection{El crecimiento con desempleo}

Hay que poner un título económico a una de las perversas consecuencias de la historia mundial: la exclusión del trabajo; ahora se habla de población sobrante, excedentaria, una sobrecarga social, una amenaza a la estabilidad política. La cumbre de Copenhague se centra en este problema que aflije a jóvenes, adultos, también a las mujeres, de países desarrollados y subdesarrollados. De ahí arrancan severas leyes antiinmigración, al mismo tiempo que el tráfico de emigrantes se ha convertido en un negocio muy lucrativo. Si a las estadísticas les damos su verdadero nombre dr rrisis de 
trabajo, crisis económica, crisis social, crisis moral y colapso mundial de incertidumbre, que desembocan en inseguridad generalizada, se aprecia mejor la gravedad del problema.

Antes decíamos que la evolución tecnológica era un proceso de creación destructiva, que afectaba primordialmente al equipo productivo: la nueva tecnología, invento-innovación, desplazaba a la ya desfasada. El proceso desplazaba a una parte de la mano activa y se comprende por qué los obreros del pasado siglo destruían las máquinas que los destruían a ellos. Pero, allá donde se hacían los inventos, se recuperaba el empleo al generar una recuperación cconómica. Con la nueva revolución tecnológica-financiera, gestada por el archipiélago del primer mundo, quedan excluidas masas ingentes de población. La exclusión laboral sería un subproducto inevitable de la historia.

Revive un neomalthusianismo ambivalente: negativo y poco humano si busca la solución en un control físico e inconsulto de la vocación generativa, o si permiten que la miseria y las enfermedades complementen el trabajo. Un neomalthusianismo más positivo y humano, cumbre del Cairo, donde tesis demasiado providencialistas deben abandonar su irrealista posición y buscar vías de autoplanificación familiar por medio de la inversión social (educación, salud-nutrición, hábital, seguridad social...), como medio históricamente más efectivo del autocontrol poblacional y de converlir la población en el factor número uno del desarrollo económico. Es cierto que esto juega a mediano plazo y por desgracia se ve contrariado por la corriente hedonista que Iransforma una vocación humana en un libertinaje del instinto, donde los medios que promelían dar seguridad terminan en el sida o el aborto. Este tema es tan importante que no cabe en la pantalla de este arlículo.

Cohabitan las dos teorías que se disputan las partidas del presupuesto nacional. En la cumbre de El Cairo se hacía la propucsta del 20-20: que el 20 por ciento de las ayudas que los países ricos envían a los países pobres se destinen a programas sociales $y$, a su vez, que los países que reciben tales ayudas se comprometan a dedicar el 20 por ciento de su presupuesto nacional a estos programas. Este compromiso se remitió a la cumbre de Copenhague, pero "no hubo acuerdo". Nuestro gobierno se ha comprometido en elevar este porcentaje al 50 por ciento del presupuesto nacional, dado que - por diversas razones- es inferior al de pasadas décadas.

Hay otra razón que debiera motivar a los gobiernos y la sociedad pudiente a tomar muy en serio la inversión social: cada vez se admite menos que la exclusión laboral sea un resultado ciego de las leyes de la oferta y demanda, sino una privación del derecho al trabajo, parte integrante del Estado de Derecho. Como este fenómeno cunde en los países desarrollados, crecen las voces de quienes reclaman una reactualización del Estado de bienestar social. Con ello, la exclusión creciente adquiere un cariz antipolitico y antimodélico: el neoliberalismo en cuestión. Esta es una nueva fuente de desestabilización política.

Ello nos lleva a reflexionar sobre una práctica corriente: se ha llegado a una situación donde parecería ser un signo de avance en la transformación gerencial las reducciones en la planilla de trabajo, lo que a veces es cierto. Sin embargo, tenemos que dar una respuesta más sincera a esta práctica de la exclusión, porque entre nosotros no se ha llevado a cabo el previo requisito de la evolución tecnológica y reconversión industrial; simplemente nos hemos montado en el último vagón del proceso tecnológico. Como dice Osvaldo Brand, sí sc han impartido múltiples conferencias y seminarios sobre planeación estratégica, transformación gerencial, reingeniería, calidad total, justo a tiempo, y otros eufemismos de moda. Tampoco la proliferación de teléfonos inalámbricos, otro prestigioso distintivo, son prueba de nuestra revolución

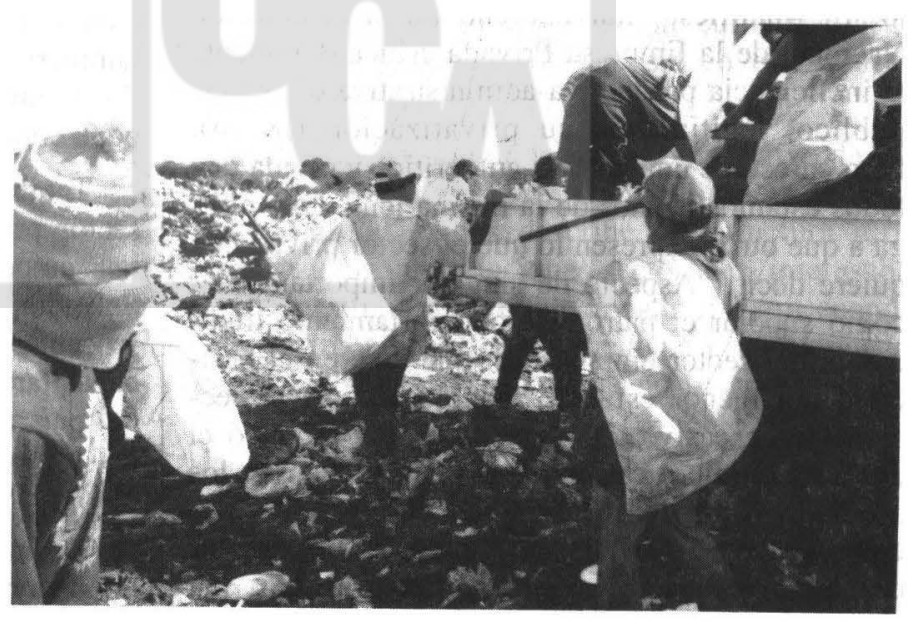


tecnológica. Llegamos con retraso y estamos generando la exclusión del trabajo sin el previo requisito de la innovación tecnológica. Esto significa que no es directamente el trabajo quien está de sobra, sino que la falla más grave está en el otro lado; hay que buscar explicaciones y correciones a esta exclusión del derecho al trabajo.

Sin marcar un orden de importancia, comenzamos por afirmar que hemos pasado dos guerras, pero las guerras no han pasado por nosotros. La guerra de 100 horas, 1969, nos costó diez años de mercado común interrumpido. La guerra prolongada de los ochenta agudizó, entre otros, tres problemas nacionales: mayor deterioro de los recursos naturales, la práctica inexistencia de reposición y actualización tecnológica y una profundización de la terciarización económica. Quienes, de un lado y del otro, votaron por la guerra debieran ahora darse algún golpe de pecho. Somos una sociedad de constrastes, incluso, en el orden tecnológico. Por decirlo de alguna manera, mientras que en el sector primario (y primitivo) del agro no hemos alcanzado la civilización del arado, en la terminal del terciario invertimos febrilmente en internets e inalámbricos. Del uno al otro extremo del circuito productivo median tres siglos de distancia, y esa laguna es una de las causales de la exclusión del trabajo.

Los tres fenómenos mencionados retroalimentan la recesión económica y la exclusión del trabajo. El Manifiesto Salvadoreño de la Asociación Nacional de la Empresa Privada critica duramente la ineficiencia productiva-administrativa del sector público, legitimando su privatización (p. 16). Pero carece de una sincera autocrítica y olvida que todos estamos hechos de la misma leña. Esto obliga a que otros expresen lo que el sector privado no quiere decir. "Aspecto de singular importancia es cómo superar el patrón de comportamiento tradicional del sector empresarial, que cree en el principio del menor esfuerzo tecnológico. El proteccionismo excesivo de varios decenios provocó el que éste eludiera correr riesgos, en particular, los asociados a la innovación tecnológica. Muchos empresarios se han acostumbrado a no competir con mejor calidad y precio; prefieren hacerlo con publicidad, acceso a crédito preferencial y la obtención de subsidios del gobierno, o sea, se habituaron a formas de competencia que exigen poco o ningun esfuerzo tecnológico, práctica que debe erradicarse para ser más competitivos" (ECA, 1997, p. 546).

Dos meses antes, una editorial adelantaba similares críticas. "El sector privado salvadoreño ha dado muestras de no estar dispuesto ni preparado para competir en una economía de mercado libre. Por un lado reclama sus libertades pero, por otro lado, se niega a invertir si no cuenta con la proteción del Estado o si éste no le otorga subvenciones y privilegios. En la práctica, no acepta una de las reglas fundamentales del mercado libre. En el otro extremo, el gobierno salvadoreño se encuentra atrapado entre las afirmaciones de su credo neoliberal y sus lealtades con el capital nacional, el cual espera de él protección y privilegios. El sector privado teme a la libre competencia y el gobiemo se siente naturalmente inclinado a protegerlo de sus vaivenes. Por lo tanto, en vistas a poner en marcha la estrategia de la competitividad, el sector privado debe cambiar su mentalidad, acomodando su conducta a los dictados de la competencia y el gobierno necesita romper sus alianzas de viejo cuño con el capital. La distinción estricta entre lo privado y lo público todavía no ha sido asimilada en El Salvador como una condición indispensable de la competitividad" ( $E C A, 1997$, p. 374). Este no es el caso de protección a la empresa nacional a que se refiere Hinkelammert, ni tampoco el entrelazamiento empresarial y gubernamental de los tigres asiáticos que se pone como modelos.

También las universidades somos parte de este sector privado y Salvador O. Brand nos invita a una autoevaluación. "En el nuevo entorno de El Salvador debe superarse el populismo académico y aceptar que la misión básica de la universidad es capacitar para comprender la cambiante realidad del país, satisfacer las crecientes demandas sociales y mejorar la productividad y competitividad" (ECA, 1997, p. 546).

Pasando de la crítica a propuestas normativas, un documento orientador es el preparado por el 
Consejo Nacional de Ciencia y Tecnología: "Estructura de la política nacional de ciencia y tecnología". Aunque a juicio de sus gestores requiere posteriores precisiones, juzgamos que este informe nos ofrece un análisis de las actuales potencialidades de los sectores productivos y, en un escenario o pronóstico de mediano plazo, 1995-2021, va detallando las políticas y estrategias tecnológicas a aplicar de parte de las instituciones oficiales, las empresas, gremiales empresariales, universidades, profesionales... Para algunos pudiera parecer un espejismo presentar un largo escenario, 19952021 , dividido en etapas quinquenales; pero leyendo las tareas por realizar, al menos tomamos conciencia del largo tiempo perdido y también se nos ofrecen acciones concretas por realizar desde nosotros mismos, si deseamos ser compañeros de vida de la inversión extranjera productiva. El peligro de estos documentos es que pasen al olvido; por cllo lo hemos integrado en nuestra revista Realidad.

A modo de paréntesis, una observación que quizás venga al caso. Actualmente somos unas cuarenta universidades que formamos profesionales de "cuello blanco"; pero, en el país hay una notoria carencia de escuelas profesionales que preparen los técnicos de "uñas azules", totalmente imprescindibles para la reconversión industrial y la transformación tecnológica. En otros países, los ayuntamientos, gobiernos locales, y por supuesto las empresas, han propiciado la creación y el financiamiento de estas escuelas profesionales. También ésta es una eficiente inversión social, no sólo por sus efectos en la producción material sino por ser un signo de dignificación del trabajo manual. Merecen elogio y todo apoyo aquellas instituciones que realizan esta doble función.

\subsection{Terciarización económica y deterioro eco- lógico}

Sobre estos dos limitantes de nuestro crecimiento económico hay suficiente literatura: un resumen ordenado y sustentado en datos estadísticos aparece en el capítulo segundo de la propuesta de FUNDE: La economía salvadoreña actual: crecimiento sin acumulación y sin desarrollo (pp. 57-

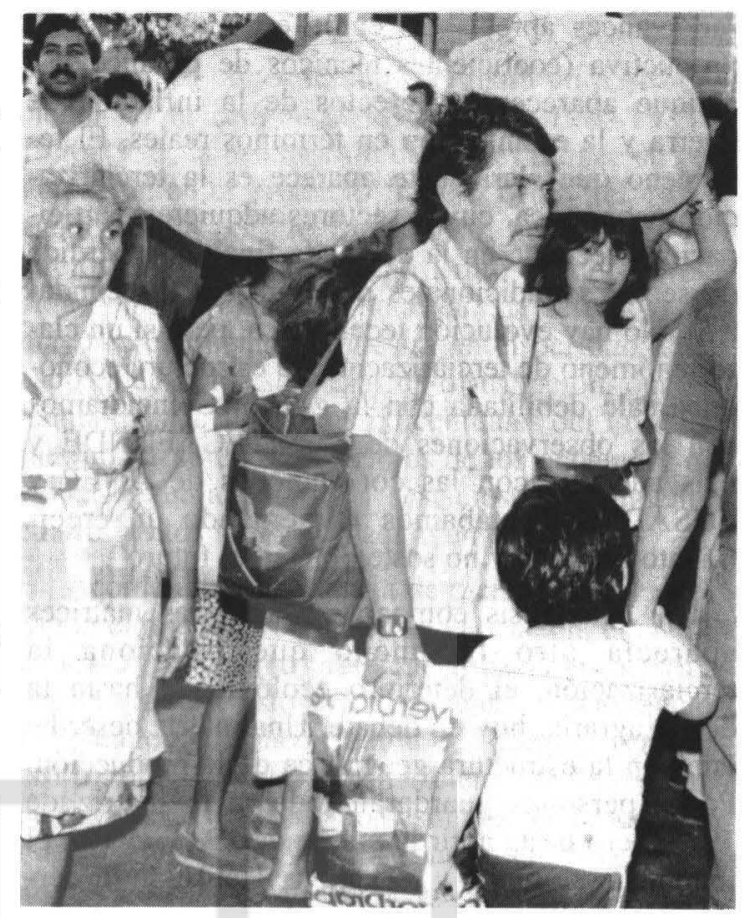

126). Disponemos de las investigaciones de PRISMA sobre la dinámica de la degradación ambiental, y el reciente análisis de FUSADES sobre el desarrollo sostenible ${ }^{\sharp}$. También el Dr. Ricardo Navarro nos alerta desde CESTA. No hace falta repetir lo que está claramente expuesto y probado en estos documentos y en anteriores investigaciones de CENITEC, IIES-UCA, FUNDE..., 1993: que nuestro crecimiento es frágil, desintegrado, no sustentable y de momento sostenido sobre flotadores externos. Precisamente, en 1993, el Banco Central de Reserva publica la matriz insumo-producto de 1990 y, por algo más que curiosidad académica, hicimos algunos análisis en el departamento de economía.

Uno de ellos fue un análisis comparativo de las matrices 1978 y 1990 . Dado que una matriz insumo-producto nos describe la estructura productiva y las interrelaciones sectoriales, interesaba conocer cómo había evolucionado nuestra economía. Entre ambas fechas mediaba el prolongado conflicto bélico. Lógicamente no se podían espe-

7. CONACYT. "Estructura de la política nacional de ciencia y tecnología", Realidad, No 56, 1997.

8. FUNDE. "Crecimiento estéril o desarrollo: bases para la construcción de un nuevo proyecto en El Salvador", 1996. 
rar avances apreciables en la estructura técnicoproductiva (coeficientes técnicos de producción), aunque aparecen los efectos de la inflación de guerra y la estanflación en términos reales. El fenómeno que claramente aparece es la terciarización económica, cuyos sectores adquieren participación creciente en la demanda final, con pérdida de sectores tradicionales del primario y secundario". No hay evolución tecnológica, pero sí un claro fenómeno de terciarización: la estructura económica sale debilitada con la guerra. Coincidíamos con las observaciones de CENITEC, FUNDE y más adelante con las concluciones de ANEP y FUSADES: "estábamos alimentando un crecimiento deforme y no sostenible en el futuro".

En el análisis comparativo de estas matrices aparecía otro fenómeno que relaciona la terciarización, el deterioro ecológico y hasta la deuda agraria, hoy en debate. Una matriz describe también la estructura geográfica de la producción. Pocas personas guardarán todavía la matriz de 1978, pero basta abrir la matriz de 1990 , ya que el fenómeno se repite y se agrava. Hablando en términos sencillos e inofensivos, decimos que el sector primario (minería, agropecuario, pesca...) se ubica geográficamente en el agro y el mar; mientras que los sectores secundario-terciario (manufactura y servicios...) descienden a las zonas urbanas. La matriz cuantifica las transacciones reales, en forma monetaria, de nuestras 44 ramas productivas.

En nuestro caso, la mayor cantidad de esas transacciones se realizan entre y en el interior de los sectores secundario y terciario desde antes de 1978, es decir, en las zonas urbanas. Mientras que la parte superior de la matriz, correspondiente a la geografía agropecuaria, abunda en "casillas fantasmas" o ausencia de transacciones. En otras palabras, los productos básicos y los de exportación fluían, los primeros, hacia la manufactura $y$, los segundos, hacia el mercado internacional. A excepción de escasas ramas, todos estos productos no recibían una transformación en su lugar de origen, no han generado la aparición de agroindustrias, de familias industriales (clusters), ni tampoco mayor valor agregado, empleo e ingresos. Los salarios han sido tradicionalmente mínimos, sobre todo medidos en términos reales ( $E C A$, 1995, p. 399...) y el desempleo estructural.

Por añadidura, el excedente de explotación agropecuario y las divisas de exportación han servido para desarrollar, en buena parte, la manufactura, los servicios y el sistema bancario de las áreas urbanas. Las fuentes de energía nacen en el agro, llegan a la ciudad pero no regresan al campo, al igual que otros productos y servicios públicos y privados. Parecería que el desempleo estructural del agro ha servido para crear el semiempleo urbano, y surge la pregunta: ¿quién debe a quién? Lo normal era que la guerra, que es algo anormal, se librara desde el agro, convirtiendo la desolación económica en destrucción física y humana. Con la guerra prolongada y la caída de los precios y volúmenes exportables, los pequeños productores y las cooperativas agrícolas celebran los acuerdos de paz con el gravamen de la deuda agraria. Esta expresión es ambivalente: deuda ¿de ellos con nosotros o de nosotros con ellos? Porque, por las mismas razones que en 1978-1990, seguimos necesitando y dependiendo del sector agrario; así lo recomiendan las diversas propuestas económicas nacionales.

Quienes de un lado y del otro eligieron la guerra, además de destruir la costosa infraestructura económica, obra del hombre y de los impuestos regresivos, deterioraron por múltiples medios la capacidad reproductiva de la tierra. En la contabilidad de la deuda agraria, ino se deben tomar en cuenta la deudas de guerra? En la condonación total o parcial de la deuda agraria debe pesar la historia y misericordia, y no sólo los déficits fiscales. Al fin y al cabo, ha sido la guerra la principal generadora de los déficits fiscales y queda por averiguar en cuánto también la privatización del sistema bancario. Tampoco sería atinado, ni económica ni socialmente, aplicar la teoría de las ventajas competitivas al gran abanico de productos agropecuarios, en las actuales circunstancias, porque las ventajas de bienes más baratos no compensan las pérdidas de ingresos, empleo y supervivencia económica. Por lo menos es menester que serios problemas sociales no se resuelvan desde la fría lógica del mercado.

9. Rubio R., Aguilar R. "Análisis comparativo de la matriz insumo-producto 1978-1990: aportes a la programación económica nacional", Realidad, No 44; Ibisate, F. J. "Aportes económicos de las matrices 1978 -1990 a los programas de desarrollo económico 1994-1999”, Realidad, No 39. 


\subsection{El crédito bancario: otro límite al creci- miento}

La historia de la terciarización y la desolación agraria se viene agravando por la indiferencia y despreocupación que el sector bancario mantiene en la canalización del crédito a los dos sectores más tradicionales. Conviene recordar que el sector bancario privado tiene una función pública por cuanto utiliza y se beneficia de un ahorro "público" o nacional. Esto debería reflejarse en la canalización del crédito hacia la dinamización del crecimiento nacional, con mayor valor agregado, nivel de empleo e ingresos nacionales. Pero ésta no ha sido la conducta de la banca privada en el pasado quinquenio. Desde el sector empresarial, la Asociación Nacional de la Empresa Privada lo advertía en su Correo Económico, octubre de 1994: "De darse un aumento en los mismos (encajes legales e intereses), los efectos sobre la inversión serían aún mayores que en la actualidad. Debe recordarse que, debido a la evolución de la economía salvadoreña, los márgenes de ganancia en actividades dedicadas a la atención del comercio y de los servicios son mayores que en el resto, lo que de por sí es un sesgo en lo que se refiere a la dirección del crédito, en contra de las actividades industriales y de producción en general, ya que su mayor período de maduración y menor margen de ganancia las vuelve menos atractivas para el sistema financiero" (p. 2).

Por las mismas fechas y desde su óptica económica, FUSADES vuelve a recordar el sesgo desviado del crédito al comentar la política cambiaria. "A manera de antecedentes cabe señalar que el panorama económico a finales de 1994 es positivo en términos de estabilidad de precios y de incremento real, con tasas cercanas al 5 por ciento. No obstante, el incremento productivo estuvo liderado por sectores de bienes no transables, a saber servicios, comercio y construcción. Dicho patrón de crecimiento no es sostenible a mediano y largo plazos, porque se da con menor participación de las principales actividades que generan valor agregado, divisas y empleo. Estas actividades corresponden a la actividad manufacturera y la agricultura, que son las dos bases de la estructura productiva de exportación, o sea, de bienes transables, que es lo que podría mantener el desarrollo sostenido de la economía, según FUSADES lo ha venido señalando" (Realidad, 1995, p. 578).

FUNDE desarrolla ampliamente, sobre datos estadísticos, el avance de la terciarización y la par- ticipación del sistema bancario en el crecimiento deforme. "El sector terciario registra un peso cre. ciente en la economía salvadoreña 1980-1983 y 1990-1993; la producción de bienes reduce su parlicipación en el Producto Interno Bruto del 44 por ciento al 31.4 por ciento; es decir, hoy más de dos tercios del Producto Interno Bruto no tienen relación con la producción material. La actividad que mayor crecimiento demuestra en el período analizado es el de los servicios de distribución, que aumenta más de 13 puntos porcentuales del Producto Interno Bruto entre principios de los ochenta y noventa, seguida por otros servicios que aumentan cuatro puntos su participación en el PIB.

Acorde a la importancia de dicho sector y reforzando el mismo proceso de terciarización, el crédito ha tenido un destino preferencial hacia las actividades de servicio. Esto ha sido patente en la evolución del crédito del Banco Central de Reserva (ver Cuadro 6): en 1990, el 57.16 por ciento de los créditos de este banco tenían como destino el sector terciario, mientras que para 1993, ese mismo crédito se había ido incrementando hasta acaparar el 80 por ciento de los créditos otorgados. Por otro lado, aunque las cifras de la evolución del crédito de los bancos comerciales e hipotecario no reflejan una tendencia clara (al menos según los datos de la revista del

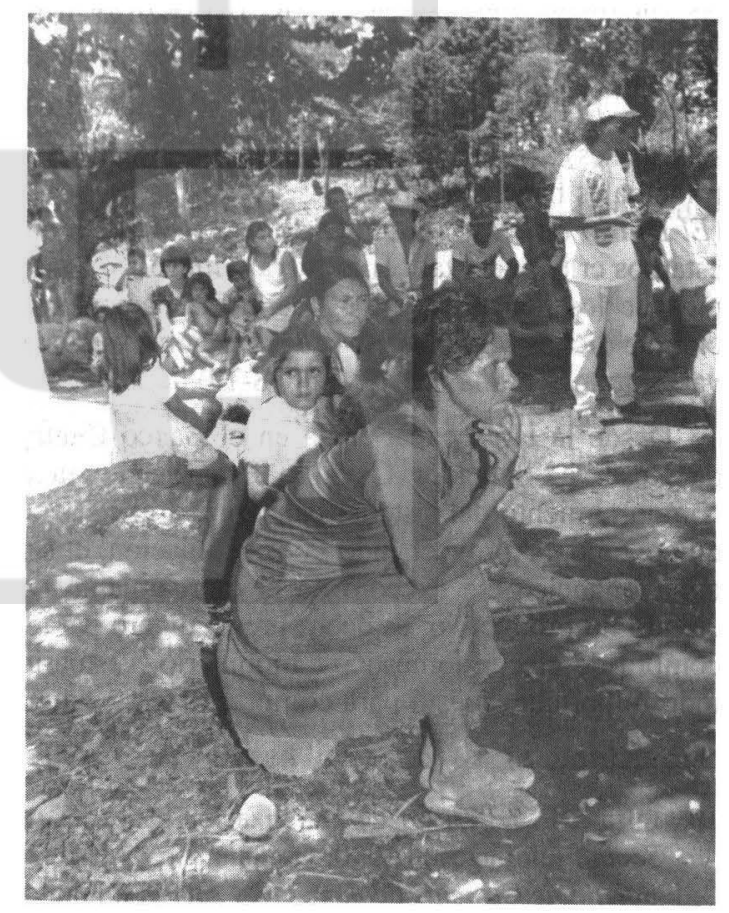


Banco Central de Reserva), lo cierto es que la mayoría se han dirigido hacia el sector terciario; por ejemplo, entre 1989 y 1991, el promedio de los créditos otorgados a este sector era casi el 70 por ciento del crédito total otorgado por dichos bancos" (pp. 74-77).

El cambio de las proporciones sectoriales dentro del Producto Interno Bruto, al igual que los porcentajes en el destino del crédito, son signos patentes de que en la presente década se profundiza la búsqueda de la rentabilidad a corto plazo, relegando el asentamiento del crecimiento real sostenido. El sistema bancario, buscando sus propios intereses, propicia esta desintegración. Por ello, la cita de FUNDE coincide con la observación que hiciera la ANEP. "En primer lugar, encontramos los altos niveles de rentabilidad que poseen los servicios vinculados al consumo (especialmente los comerciales y financieros) respecto a las rentabilidades que presentan los capitales invertidos en la agricultura e industria. Esta rentabilidad sectorial desequilibrada es uno de los factores que impulsan y estimulan el actual proceso de terciarización.

Así, por ejemplo, un analista financiero (al parecer cercano a la banca $y$ bien informado) calculaba recientemente unas utilidades netas de aproximadamente 391,000 colones diarios $(71$ millones en seis meses) en uno de los principales bancos del país

(El Diario de Hoy, 15 de agosto de 1994)... Lo que estamos criticando, tal como fuera criticado incipios de los ochenta y que generara la nacionalización de dichos servicios, es la actitud voraz que nuevamente muestra la banca" (pp. 78-79).

Desde la larga experiencia en el Banco Central de Reserva, Salvador Osvaldo Brand enjuicia el comportamiento del sistema bancario en el presente quinquenio. "Aprovechando la desregulación, el sistema financiero se excedió en el otorgamiento del crédito no productivo, es decir, prestó dinero para la compra de electrodomésticos, mobiliario, vestuario, todo importado; prestó para comprar dólares, adqui- rir automóviles nuevos y usados, viajes, compras especulativas de bienes raíces, y también para acumulación de inventarios, previo al aumento del impuesto al valor agregado y de las tarifas de servicios públicos. Naturalmente, no hubo ahorro por el exceso de consumo que se reflejó en un crecimiento excepcional de las ventas comerciales, aun cuando las tasas de interés eran elevadas. A la par de todo eso, el gobierno no previó estímulos para la producción agrícola e industrial... No obstante lo dicho, es notable que en la composición del producto interno bruto, el sector financiero es el que ha obtenido mayores beneficios por el elevado diferencial entre las tasas activas y pasivas que se traduce en una alta rentabilidad, pero más que todo por el abuso en el cobro de comisiones por los servicios, no del todo eficientes, prestados al público..." Más adelante recomienda al sector financiero "reflexionar hasta cuándo podrá llegar la "luna de miel" del predominio de las operaciones especulativas sobre las operaciones de apoyo a la producción nacional" ( $E C A$, 1997, pp. 538 y 542).

En 1986, en plena guerтa civil, con ocasión de la publicación de la matriz-1978, hacíamos dos investigaciones complementarias en el departamento de economía. Esta matriz nos indicaba cuáles eran los quince sectores más importantes en cada uno de los aspectos siguientes: valor bruto de la producción, sectores más oferentes de insumos, sectores más demandantes de insumos y mayor participación en la composición del valor agregado. Estas serían las ramas con mayor capacidad de dinamizar el conjunto de la economía si hacia ellas se canalizara el crédito bancario. Actualizamos el estudio en 1990, con ocasión de la privatización del sistema bancario. Al mismo tiempo aparecía que entre los sectores con alta capacidad de dinamizar o catalizar la economía general se situaban aquellas ramas que dan respuesta a los productos-servicios de la canasta básica. Titulamos esta investigación: "Necesidades básicas y reactivación de la economía"'0. La intención era

10. Ibisate, F. J. "La ley de privatización bancaria: ¿de la privatización a la privatización?", Realidad EconómicoSocial, julio-agosto, 1990; Orellana A. y Alfaro J. "Necesidades básicas y reactivación económica" (resumen), Boletín de Ciencias Económicas y sociales, julio-agosto, 1987. 
mostrar que si el modelo de postguerra deseaba evitar una de las causales de dicha guerra (la insatisfacción de las necesidades básicas familiares), una solución al doble fin del bienestar social y recuperación económica era regenerar la integración sectorial, prestando mayor atención a la demanda popular. También creímos que con el Plan de Reconstrucción Nacional, además de ganar votos electorales, algo se avanzaría en la línea de una economía social "con mercado". Ahora, todo esto es parte de lo que el viento se llevó.

Es lógico y necesario que las propuestas económicas 1993-1997 vuelvan a enfatizar medidas concretas hacia la integración sectorial, so pena de derivar hacia una economía imposible. Hemos llegado a un entrecruce de callejones sin salida: la terciarización económica, que a la vez fomenta y procede del rezago tecnológico, afectados ambos limitantes por la depredación del medio ambiente y el contrasentido del crédito bancario, nos han llevado a la reducción de "nichos productivos" para la inversión productiva. Al ir cerrando estas oportunidades, no quedan otras alternativas que la inversión especulativa en servicios públicos por privatizarse, en comunión con la inversión extranjera y/o la inversión especulativa en el mercado financiero. Dolorosamente, hasta los depositantes de Insepro-Finsepro..., víctimas de la especulación financiera, han comprendido que eso no es hacer economía. Concluimos que tampoco es cierto que nuestro sistema bancario sea "sólido", cuando más bien ha contribuido a un mayor debilitamiento de la estructura productiva.

Rodando la película hacia atrás, con miras a lograr un sano crecimiento, debemos programar cinco áreas de acción económica a mediano plazo: la integración sectorial versus la terciarización; el aprendizaje-aplicación de los avances tecnológicos, adecuados a nuestra estructura económica, para lo cual pueden ayudar los programas de CONACYT, en cuanto crean conciencia del pro- blema y proponen acciones conjuntas por realizar. La labor de información y acción conjunta del Ministerio del Medio Ambiente con instituciones privadas, Organismos no Gubernamentales y universidades, con la finalidad de combinar las alternativas técnicas con el control legal y la disciplina correctiva. Los repetidos fraudes financieros y la misma interpelación al presidente del Banco Central de Reserva requieren una revisión de las seis leyes y reglamentos del sistema financiero. Pero, el problema mayor está en el comportamiento oligopólico de la banca privada.

No estaría de más que las autoridades monetarias releyeran el análisis de nuestro sistema financiero, preparado por una misión alemana en mayo de 1989, con sus propuestas y recomendaciones". No basta acusar el centralismo de la Junta Monetaria (19721989) para justificar la excesiva desregulación que termina en oligopolio bancario. La misión alemana insiste en la "profesionalización de los agentes bancarios" y recomiendan el cercano control de la superintendencia del sistema financiero. Entre tantas cosas importantes dicen: "El fin último de la política estatal en el ámbito financiero es apoyar el mejoramiento de las condiciones de vida de la población". Esto responde a la filosofía de la Economía Social de Mercado "a la alemand".

También sería conveniente que el gobierno y su comité económico recuerden lo que el señor Presidente dijo el primero de mayo y repitió el primero de junio: "la formulación de un Plan de Desarrollo Nacional, con una visión de mediano y largo plazo, que nos lleve al desarrollo y genere estabilidad y confianza... (El Diario de Hoy, I de mayo de 1997). "Necesitamos tener una visión de largo plazo para dar estabilidad y continuidad al país, más allá de los períodos de gobierno, a fin de convertir a nuestro país en un lugar atractivo para la inversión y generación de empleo, que eleven el bienestar y calidad de vida de la población"

11. CENITEC. "El sistema financiero de El Salvador: análisis y perspectivas", mayo, 1989. 
(Idem., I de junio de 1997).

Literalmente, en estos discursos se reconocen serios fallos en la conducción económica: no hay un plan nacional de desarrollo, a menos que se adopte el plan trienal del Banco Mundial (ECA, 1997 , pp. 365...). No hay una visión de medianolargo-plazo, estabilidad y confianza, c implícitamente se reconoce el desafío del empleo, del bienestar social y de la calidad de vida de la población. Con la mejor intención, estas palabras vienen a confirmar que, a similitud del entorno mundial, tenemos un crecimiento sin equidad. Cerrando el circuito, las seis "coyunturas", comentadas en la primera parte de este comentario, han puesto su nido entre nosotros. Nuestro ser económico es una simple parcela de la economía mundial, que queda reflejada en la introducción del F.Hinkelammert en su artículo: "El huracán de la globalización":

"El proceso de la globalización pasa desde hace más de dos décadas por encima de América Lalina, así como pasa por encima del mundo entero como un huracán. La privatización de las funciones del Estado, el libre comercio, el desencadenamiento de los movimientos internacionales de los capitales, la disolución del Estado social, la entrega de las funciones de planificación económica a las empresas multinacionales y la entrega de la fuerza de trabajo y de la naturaleza a las fuerzas del mercado han arrollado el continente". La globalización no puede ocultar sus efectos, y la creciente toma de conciencia, continental y mundial, conduce no sólo a la crítica de este modelo que se presenta como el fin de la historia, sino a una autocrítica de los modelos que la han precedido y que, por sus errores, la han engendrado. Si al terminar el siglo 19 se hace una multipolar crítica de su historia y se escribe la "Rerum Novarum" (los nuevos acontecimientos), también al final del presente siglo y milenio se actualiza la autocrítica, dando a entender que el siglo XXI debe construirse corrigiendo los errores del ya cansado siglo XX. La globalización no camina sola.

\subsection{EI regreso de los "NEOS"}

La historia del siglo XX está hecha de una cadena de teorías y neo-teorías, modelos y neo-modelos, que pretenden sobrevivir por un proceso de reencarnación o de clonación que mejore la especie. Tenemos clásicos y neoclásicos, liberales y neoliberales, keynesianos y neokeynesianos, socialistas y neosocialistas, estructuralistas y neoes- tructuralistas, sin olvidar los neofundamentalistas, que tampoco están de acuerdo con la globalización. Esto es prueba de que a todos nos cuesta renunciar a nuestro árbol genealógico. Lo importante es que este regreso de los "neos" encierra una dosis de culpabilidad, de autocrítica de los errores cometidos en el pasado, junto con otra dosis de autosuficiencia para conducir y normar el futuro. Cada uno podemos sentirnos más allegados a alguno de estos modelos, o bien podemos ser hombres de búsqueda de una tercera vía, porque ninguno de los "grandes modelos" ha dado una respuesta humana al conjunto de problemas económicos, políticos, sociales e incluso ecológicos.

La proliferación de tanto "NEO" nos lleva a otra reflexión. No basta que las personas seamos hombres de búsqueda de nuevos modelos; son los modelos los que tienen que emprender la búsqueda de lo "nuevo", para encarnarse en la nueva realidad y ofrecer respuestas realistas a sus desafíos. Este breve artículo ha pretendido diseñar, en forma de simples pinceladas, esas realidades, aquí llamadas coyunturas, que tipifican el fin del siglo mundial y nacional. No me pronuncio por ningún modelo económico, porque creo más importante que los modelos económicos se pronuncien y se definan de cara a los desafíos aquí mencionados. Por supuesto que la realidad es más amplia y compleja que estas seis coyunturas, pero también es cierto que ellas extienden sus tentáculos a otros órdenes y esferas del agregado nacional.

Si proyectamos sobre el tablero nacional los resultados de estas seis coyunturas, podemos armar un mosaico de nuestra estructura económica. Estanflación significa crecimiento frenado con alza de precios. Si al crecimiento frenado le restamos los gastos derivados del deterioro del medio ambiente, equivalentes al 5 por ciento del Producto Interno Bruto, el crecimiento real desciende a la tasa "cero" e, incluso, comienza a ser negativo. Si recientes investigaciones revelan que las pérdidas directas e indirectas de la creciente violencia equivalen al 14 por ciento del Producto Interno Bruto, el crecimiento real queda diezmado. Si el crecimiento presente se ve seriamente limitado por el agotamiento de los recursos naturales, se alza un serio interrogante para el crecimiento sostenible futuro. Si el crecimiento global se realiza con desempleo, simultáneamente se está debilitando la demanda global presente y futura, y se recalienta la mecha de la inestabilidad política. Similar efecto 
tiene el crecimiento con desigualdad, porque por doble vía se suma la exclusión del trabajo.

Si se integra la terciarización económica con el retraso o desculturación tecnológica, se debilita la capacidad de recuperación de la oferta global, o sector produclivo, y también salen excluidos del sistema un porcentaje elevado de productores privados; la economía formal se hace menos formal, mientras crece la economía informal. Con la reducción de los nichos productivos en el más amplio sector productivo de la economía, el ahorrocapital busca su salvación en la cacería de la privatización, con el parabien de los gobiernos, o se recurre a la inversión especulativa y aleatoria del capital financiero. Con el entorno de violencia física y de inseguridad jurídica, llamada corrupción, tampoco se hará presente la inversión extranjera, sostenidos de momento por los flotadores externos, remesas y otros menos dignos. Parece que nuestro esqueleto económico tiene los pies de barro, como la estalua de Nabucodonosor.

Traduciendo esta estructura a un sencillo modelo macroeconómico nos encontramos con un conjunto de variables desintegradas. Lo que llamamos Producto Interno Bruto es un mosaico destrabado de dos sectores contra uno, con el aval del sistema bancario. Con ello, ni el nivel de empleo, ni la demanda efectiva de factores de producción pueden elevarse desde arriba, debido al crecimiento deforme del Producto Interno Bruto. Difícilmente puede catalizarse desde abajo, desde sus determinantes: la oferta global está seriamente debilitada por el desfase tecnológico y el deterioro de los recursos naturales. Ello reduce las ventajas competitivas y eleva los costos de producción. También la demanda global se ha ido debilitando estructuralmente: el consumo se alimenta de un elevado porcentaje de bienes finales importados, relegando así la oferta global interna. El consumo se resiente doblemente por la acción simultánea de la inflación prolongada y el desempleo o exclusión de mano de obra activa. La oferta no crea la demanda y, en consecuencia, la demanda' no crea ni la oferta ni la inversión.

$\mathrm{Al}$ ir pasando de una economía basada en la producción y en el trabajo a una economía deslumbrada por las importaciones finales (ventajas competitivas y efecto-imitación del primer mundo), se contrae la importación de bienes intermedios y de capital en dos de los tres sectores económicos. La inversión privada productiva ve reducido el abanico de sus expectativas futuras, y la inversión pública, física y social, dependerá de las partidas del presupuesto y de los recursos que le deje el proceso de privatización. Accidentalmente, la estabilidad del tipo de cambio, sumado a las desventajas competitivas, alientan más las importaciones finales que las exportaciones intermedias y finales. El sistema bancario alimenta sus propios intereses, olvidando que el auge financiero no puede perdurar sobre un debilitado sector real productivo, mientras que el gobierno sustituyó al ministerio de planificación económica y desarrollo social por el laissez-faire del mercado y la exportación de la buena imagen nacional.

Si todo esto no es una falacia económica, y no pretende serlo, el neomodelo por construir, entre todas las propuestas ya presentadas y por presentar, se enfrenta con una estructura desintegrada de variables y, sobre todo, de comportamientos económicos. La presentación de este esqueleto económico tiene una finalidad constructiva. Aunque la tarea de reorganizarlo es compleja y a mediano plazo, un primer adelanto es señalar las áreas débiles y debilitadas del mosaico económico. No todas las propuestas gozan del mismo realismo económico y, en este sentido, debe estudiarse con especial atención el proyecto económico de FUNDE, que para algunos analistas se acerca a un enfoque neoestructuralista. El problema es que las propuestas con mayor realismo económico no gozan del apoyo del mayor poder político.

Todo lo anterior nos lleva a una conclusión final: el nuevo modelo económico no puede armarse desde los grupos del poder financiero y sus acólitos, porque ello pondría en serio peligro el equilibrio económico y la estabilidad política. Hay que armarlo desde los que integran la demanda y la oferta deficientes, porque esto significa priorizar la inversión social, el consumo interno, la inversión productiva, la recuperación ecológica, la actualización tecnológica, la creación de empleo, la infraestructura económica y también un gobierno que sea Estado. $\mathrm{Al}$ fin y al cabo, para que las empresas sobrevivan es menester que la humanidad viva. 